\title{
Multimodality in Safaricom Advertisement Communication in the Kenyan Daily Nation Newspaper
}

\author{
Yakub Adams \\ Department of Linguistics, Maseno University \\ Peter M. Matu \\ Department of Languages and Communication Studies \\ Technical University of Kenya \\ Omondi Oketch \\ Department of Languages and Communication Studies \\ Technical University of Kenya
}

\section{Doi:10.5901/ajis.2014.v3n6p403}

\section{Abstract}

Advertising is a form of communication which has one main function: to make the audience buy the advertised product or subscribe to the services displayed. Consumer advertisements employ more than one mode of communication in designing messages that target their audiences. This often causes interpretational difficulties to the target audiences. This study examined how language co-occurs with the other semiotic forms as used in Safaricom advertisements. The study examined how the visual texts in Safaricom newspaper advertisements impact on the audience's purchasing decisions, analyzed how visual semiotics and written language were used in the Safaricom advertisements to aid meaning interpretation and determined the impact of using the visual images and written language on the audience's ability to interpret the messages. The data analysis was based on Multimodal Discourse Analysis (MDA) a theoretical framework by Kress and Van Leeuwen.

Keywords: Safaricom, Advertisements, Semiotics, Multimodality, Interpretation,

\section{Advertisement and Safaricom Telephony}

It is more than likely that an advertisement would influence the consumer by defining 'reality' in a sense that is consistent with and conducive to the consumer economy. An advertisement also socializes him into thinking that he can buy a way of life as well as goods. It can be argued that prolonged experience of advertising and other commercial texts contribute to shaping peoples' identities as consumers. Advertising is not merely business expenditure for moving merchandise but a vast array of symbols and ideas that are an integral part of modern culture (Leiss, Kline \& Jhally, 1986). Advertising has been linked to religion, modern showmanship, and patriotic goals in wartime and popular culture. An advertiser's intention is to give meaning to a product by developing associations in the mind of the reader or listener and persuading them to buy it. These associations are cultural in the sense that any member of the culture for which the advertisement is produced will find them easy to recognize. It is important to understand the concept of advertising in ways that would assist both the advertiser and the audience to achieve successful communication.

Dyer (1982) posits that an advertisement is a message that is aimed at persuading readers or listeners to buy a particular product, favor a particular organization or agree with a particular idea. In addition, just as McDonald (1992) observes, advertisements are all around us: in our daily newspapers, magazines, on hoardings in the street, on buses and assailing us from the radios, televisions and the cinema. Each of these means of advertising has what the advertiser relies on most for effective communication.

Furthermore, Dyer (1982) asserts that advertising uses language distinctively and that there are certainly advantages in making bizarre and controversial statements in unusual way as well as communicating with people using simple, straightforward language. An advertisement may not attain the goals of selling goods, services or ideas not only because the target audience was not exposed to the advertisement but also because the language used did not suffice to grab the attention of the audience, captivate their interest, create a desire and move them to action. It could as well be 
that the message was not understood and conveyed a different meaning to the target population.

In print, the visual text illustrations are presented and the language plays a variety of roles such as attracting attention, illustrating visual images and presenting information. Due to advertisers' main objective of enabling people to identify a product and also remember its name for persuasion's sake, advertisements not only rely a lot on the use of language but also the visual images. Crystal (1997), argues that, in most cases, it is the visual content and design of an advertisement that makes the initial impact and causes the audience to identify with the product, remember its name (or at least make them feel that it is familiar) and persuade them that it is worth buying.

This paper intends to show that Safaricom advertisements use visual texts in order to attract and persuade the audience. Safaricom is a popular Kenyan mobile phone network provider. It is possible that its popularity may be due to effective audience outreach through advertisements. However, it should be said that advertisements should not be taken at face value but that the audience needs to look critically at them. The visual texts in Safaricom advertisements could be misleading and may often cause misinterpretation. The use of language and images cannot be excluded from factors that cause the success or failure of any advertisement. Therefore, this study sets to investigate how advertisers package their messages and how they exploit language and visual images to attain their objectives. The liberty to breach the rules of grammar plus the unfamiliar visuals may cause a problem hence the need to study and explain how Safaricom newspaper advertisements texts are interpreted by consumers of the telephony service.

Advertising as a means of reaching the target audience for the various services offered by Safaricom would be important as it promotes ways of life that the mobile phone company aspires for its subscribers to identify with. The advertisements are expected to promote various forms of lifestyles that mobile telephony has initiated. The advertiser intends to make the audience to view the modern life differently and as dictated by the mobile phone technology. This study has used the Safaricom advertisement from the Daily Nation newspaper, that is published in Kenya, to investigate the interpretations that viewers may allude to in the advertisements.

\section{Gaps in Knowledge}

Building on this ability of interpreting messages in advertisements, Harris (1983) conducted an empirical study of inferences in the context of advertising. According to him, it is assumed that inference in advertising is a negative process, thus it can and should be avoided. He proved the efficiency of training techniques for people to detect and doubt misleading claims in advertising. However, the process of inference drawing is a constituent part of any form of meaning making. This study attempts to assert that inference in advertising is not a negative process but a positive and important aspect of interpreting the encountered advertisements. The Safaricom advertisements which touch on the visual entity have to be understood by the viewers. There must be an interpretational process and this study hopes to achieve this ability.

While Harris (1983) analyzed inferences in advertising, Fairclough (1992), who was concerned with the analysis of pressuposition in discourse, says that one is capable of saying one thing and meaning another. This is what can be said to make up what is asserted and that which is implicated. Sperber and Wilson, cited by Fairclough (1992), expand this to include the intertextual nature of implicatures. This means that implicatures can be construed to mean what is echoed in another person's utterance. This is evident in the obvious mismatch between what is apparently meant from the surface meaning and the situational context of what is said. This contribution by Fairclough assists the current research in denoting the importance of interpretations and understanding the Safaricom advertisements. The study moves further from Fairclough's assertion by making interpretations based on the co-occurrence of the image and texts in the advertisements.

Cook (1992), while deviating from Fairclough (1992), gives a detailed study of advertising as a discourse type from a functional perspective and is complemented by further comments framed within the field of linguistic stylistics. He posits that the language of advertising will involve a functional purpose to enable the process of communication to be complete. This discourse will be through the usage of language in more appropriate manner as seen by the copywriter (this might involve even unconventional usage). Cook (1992) talks about the description of the context(s) of advertising and the function(s) of advertising discourse, together with a specification of the relations that are established between the advertiser and the audience. Secondly, he further gives a description of some typical linguistics textual devices which are exploited by advertising discourse to pursue a communicative purpose. This study has borrowed heavily from functional linguistic thus considers Cook's assertions significant in the pursuit of meaning making in advertisements. This study though ventures into the new field of multimodality in text analysis.

The venture into the multimodal communication depends also on the study by Jefkins (1994), who gives an insight 
into the aspects of consumer advertising. He describes what the consumer advertising entails by giving attributes of consumer goods as well as consumer durables. On the issue of language, he outlines several copy devices which equip the copywriter for effective advertisement writing. These devices include buzz words, action words, colloquialisms, alliteration, emotive words, punctuation and grammar. Most copywriters would employ these devices to put across their message and the audiences are expected to make the right interpretation to understand the advertisement. The present study moves a step further than Jeffkins (1994) and analyses the multi-semiotic aspect in interpreting advertisements. Although audiences are exposed to much advertisement, advertising may deceive either by increasing a consumer's false belief or by exploiting a true belief in the ways designed to sell the product.

This issue of deception was examined in some depth by Harris (1999). He distinguished between several types of linguistic constructions that may deceive the consumer without actually lying. Such claims may invite the consumer to infer beyond the information stated and thus construct a stronger interpretation. The constructions described by Harris are hedges, elliptical comparatives, implied causation, implied slur on competition and pseudoscience. These constructions provide useful information on the language techniques employed by the advertisers and thus assist this study as the interpretation of advertisements from the visual entity is of a major concern in this study.

There are also some other studies on advertising that have contributed to the linguistic aspect of advertising. Ombongi (2003) has used Halliday's Systemic Functional Grammar (SFG) to show how advertising language realizes its persuasive intention using the interpersonal function of style. The study ventures in advertising in the print media and particularly discusses advertisement on telecommunication in Kenyan Newspapers. Another study, Muchura (2004) also applying SFG looked at advertising using women images in Kenyan magazines. She unlike Ombongi (2003) concentrated on the textual function of style in advertising and concludes that advertising register of Kenyan magazines is identifiable as a register with its own unique style. The two studies mentioned above ignored the relationship between the advertiser and the audience when it came to how interpretations of the visuals in advertisements are carried out. They, at the same time, did not analyze the visual social semiotic contents of the advertisements. This study, therefore, deviates from these two studies to analyze the visuals in an interpretational process and denote the impact advertisements have on the audiences.

\section{Discourses as Concept}

The study of discourse has developed in a variety of disciplines - sociolinguistics, anthropology, sociology, and social psychology. Thus discourse analysis takes different theoretical perspectives and analytic approaches: speech act theory, interactional sociolinguistics, ethnography of communication, pragmatics, conversation analysis, and variation analysis (Schiffrin, 1994). Although each approach emphasizes different aspects of language use, they all view language as social interaction. In this paper, Multimodality of aspects of communication is taken into great consideration.

The notion of discourse may be employed to refer not only to linguistic uses but also to other types of nonverbal communication and even to any form of semiotic activity, visual images included. Fairclough and Wodak (1997) state that Social Semiotics may be located within the broader field of 'Critical Discourse Analysis' which is likewise to be understood as a major research tradition of 'Discourse Analysis' as a domain specialized in unveiling the close relations among language, ideology and power in society. They further put it that Social Semiotics draws attention to the multisemiotic character of most texts in contemporary society and explores ways of analyzing images and the relationship between language and visual images (pg 164).

Oketch (2006) carried out a study on language use and mode of communication in community development projects and concluded that the success of a mode of communication depends on a critical consideration of the register aspects of discourse, which in turn demands a thorough understanding of the experiential, the interpersonal and the textual resources available to the target participants. Oketch's study concentrated on multimodal communication in activities aimed at development projects as promoted by Non Governmental Organizations while the current study has analyzed the usage of multimodality in the commercials in the print media.

\section{Multimodal Discourse Analysis: A Theoretical Framework}

This research analyzed written language and the visual image on Safaricom advertisements appearing in the Daily Nation newspaper. When one looks at an advertisement which consists of both visual images and verbal captions, both elements come into the viewer's eye as a visual entity. In order to account for the possible interpretations from an advertisement the Multimodal Discourse Analysis (MDA) model is employed. According to Jones (2012) Multimodal 
Discourse Analysis is an approach to discourse which focuses on how meaning is made through the use of multiple modes of communication as opposed to just language.

ledema (2003) posits that the term multimodality was introduced to highlight the importance of taking into account semiotics other than language-in-use, such as image, gesture, and so on. The increased ubiquity of sound, image, film, through TV, the computer and the internet is undoubtedly behind this new emphasis on and interest in the multi-semiotic complexity of the representations we produce and see around us. The term multimodality, as used here, is a technical one aiming to highlight that the meaning work we do at all times exploits various semiotics. Multimodality aims at offering a way of examining, for example, how language and image work together (Kress and Van Leeuwen, 1996; Eggins and ledema, 1997) or how gesture and talk co-occur (Martinec, 2001).

Multimodality, then, provides the means to describe a practice or representation in all its semiotic complexity and richness. Multimodal Discourse Analysis framework was developed by Kress and Van Leeuwen (1996) as a grammar of visual social semiotics. Visual social semiotics is functionalist in the sense that it sees visual resources as having been developed to do specific kinds of semiotic work. They operationalize MDA by extensively making its tenets namely; Representational (Experiential) meaning, Interactive (Interpersonal) meaning and Compositional (Textual) meaning appropriate for analysis of Multimodal texts. This justified its choice as a framework for data analysis in this present study.

\section{Methodology}

This was a qualitative research that carried out a study of Safaricom advertisements appearing in the Daily Nation. A total of sixty three Safaricom advertisements published in the Daily Nation were examined. In a larger research project which yielded data for this paper twelve Safaricom advertisements out of the sixty three were selected by a purposive sampling of the advertisements available to represent the population. This was the number used in the data presentation and analysis for the larger project. For the purposes of this paper's objective, two advertisements will be used.

The researchers also used snowballing technique to sample the population of respondents in order to come up with a sizeable and controlled number that would make the work manageable and practical within the time frame and resource available for the study. A total of ten respondents were engaged in audio-taped interview sessions. This paper approached the analysis of the collected data from a semiotic perspective. The semiotic analysis was strictly descriptive and it involved identifying instances of meaning making as derived from Representational meaning, Interactive meaning and Compositional meaning.

\section{Data analysis and discussion}

The data presented was analyzed at various identifiable thematic levels. This paper presents two of the thematic levels namely: Information on Products and Services and Family and Love which will be demonstrated by the use of two advertisements.

Advertisement \# 1: You Talk, We Listen

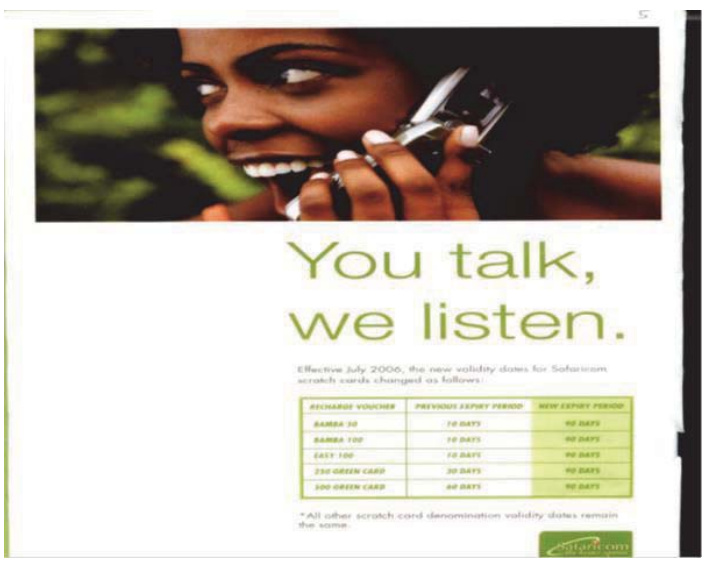

An aspect of service Safaricom offers its subscribers is shown in advertisement \# 1 above. This advertisement makes a 
non-transactive effect on the audience. It is noted that the action in a non-transactional structure has no 'Goal' is not 'done to' or 'aimed at' anyone or anything (Kress and Van Leeuwen, 1996). We do not manage to see the person she talks to and thus we are left to speculate. The lady is the 'actor' but the goal is not exposed to us. However, she appears quite thrilled in the process of communicating. Jewitt and Oyama (2001) expound this by stating that facial expressions and gestures can then 'colour in' the nature of the reaction as pleased or displeased, deferential or defiant and so on. The lady using her mobile phone appears quite thrilled in the process of communicating. This advertisement is about subscribers talking to Safaricom 'who' is ready to perform the subscribers' 'demands'. Seemingly, there were suggestions about the validity dates (periods) on scratch cards put forth by Safaricom subscribers and now, the company has done what the subscribers were calling for.

The phrase 'you talk, we listen' means that the subscriber (you) does the talking and makes demands while Safaricom (we) is a willing listener who would proceed to fulfill the 'talk' from the subscribers. It can also be deduced that Safaricom is taking demands from its customers. This, in effect, is meant to entice the subscribers to have confidence in the company as one that takes its subscribers seriously and does what they want. The lady in the image has her eye-line gazing at a 'goal' the viewer cannot see. We can then assume that she is looking at and talking to Safaricom who does the listening to the 'demands' and 'suggestions' she is making in her phone. Her looks suggests satisfaction and contentment or even happiness to serve clients in case one interprets the texts as a public relations tool. In the latter case she projects a loving image which is part of the good public relations. This represented participant looks away from the viewer and at an unknown goal therefore she can be considered as an offer image in interactive meaning making terms (Kress and Van Leeuwen, 1996). She just provides information about the new validity periods (duration) of the Safaricom scratch cards on offer. She also 'offers' information on the ability of Safaricom to listen to its subscribers when they have issues to raise. Safaricom appears here as a company that prides itself as one that offers its subscribers the services that they need.

The represented participant depicted in the advertisement is one of intimate distance derived from the close-up shot nature of the image. The image provides the viewer with an interactive meaning making proposition. To see people close up is to see them in the way we would only see people with whom we are more or less intimately acquainted, as Jewitt and Oyama (2001) assert, it is when every detail of their face and their expression is visible. In this advertisement, this aspect of interaction makes the viewers feel like they are the ones making the phone call to Safaricom to state their needs. Safaricom would also want to make subscribers feel that they are considered as close members of the company who also control decision making process of the company.

On a further analysis of this advertisement, we denote that the lady, the represented participant, is put as an ideal value of information while the validity period of Safaricom scratch cards is placed as the real value of information in the advertisement. This analysis follows Kress and Van Leeuwen's (1996) postulation that those elements placed at the top of the image have an ideal value contrary to the real character and down to earth information of those situated at the bottom. The implication of this assertion is that the aspirations of many a subscriber might be to enjoy the goodness of the service just like the lady speaker which is quite ideal while the real and down to earth information which Safaricom provides is the truth of validity period. The advertisement wants the subscribers to enjoy the new validity period which is also graphically presented in the advertisement. However, some respondents had difficulty with interpreting this text. One respondent pointed out that:

"I will be having problems interpreting some of them. For example, this advertisement on validity dates for Safaricom scratch cards has a lady talking on her phone. She has a Motorola phone, and does this mean that this is the best phone? Does it then imply that other phones would not be good? I think the images in the advertisements have to consider the biases and status of the audience."

It then implies that some viewers miss the intended meaning of the text because of the images used. The images like the Motorola phone gives mixed impressions and some respondents thought it was advertising Motorola phones.

The real value of information at the bottom part of the advertisement is also the most salient in the interplay between image and word inscriptions. The inscriptions are made more salient to imply that this is really what Safaricom wants the viewers to get. It provides the information of the extension of expiry periods of the various Safaricom scratch cards on offer. They, thus, intend to appeal to more subscribers and would be subscribers to feel secure in the use of their airtime and not to panic due to the validity of their scratch cards. They aspire to appeal to the comfort of the subscribers and the company's ability to provide the services and information its subscribers require.Safaricom in their quest to create affordability in their products came up with

a scratch card which they consider to be in tandem with the financial ability of their subscribers. From the text one 
can also deduce that Safaricom targets people from all levels of income hence projecting the capitalistic tendency of controlling the market in order to maximize on profit. This can explain the huge profit margins Safaricom realized in 2006 (Daily Nation, 10th December 2006).

Safaricom also enhances the concept of family love and ties. This theme runs through most of the advertisements placed by this telephone network provider. The following advertisement is an example of such an initiative by the company.

Advertisement \# 2: Save 50\% All Easter Weekend and Every Weekend

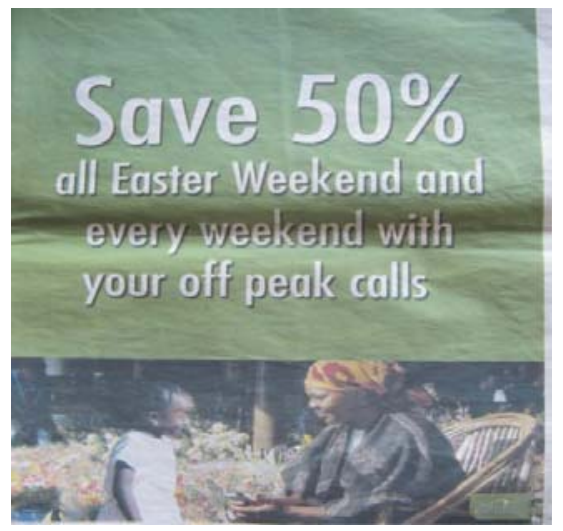

Take for instance this advertisement \# 2 whereby the represented participants are seen in a homely environment. This is an advertisement that explores the essence of vector, goal and actor to formally communicate the intended message to the target audience. Kress and Van Leeuwen (1996) describe visual syntactic patterns as having the function of relating participants to each other in meaningful ways. The narrative representations which relate participants in terms of 'doings' and 'happenings' of the unfolding of actions, events or processes of change are aptly employed in this advertisement. They add that when a narrative visual proposition has two participants, one is the Actor, the other Goal. The Goal is the participant at whom the vector is directed; hence it is also the participant to whom the action is aimed (Ibid, 1996:62).

In the advertisement, there are two represented participants in the image given. Here, the vector is formed by the strong diagonal eye line of the old lady (presumably, mother) and the little girl is the goal of her gaze. The old lady is holding a phone in her hand but her interest is on the child. The message the image narrates is the fact that there is happiness depicted by the smiles on the participants' faces. The caption accompanying the images is about saving money that is save $50 \%$ all Easter weekend and every weekend with your off-peak calls. It means that with the savings made on calls, there will be some money left for other things in the family. The mother's direct gaze on the girl implies that there are good things she can now do for the child with the saved money. The smile on the girl's face depicts a presumed gratitude thus Safaricom promotes close-knitness in families from phone calls savings.

The mother and the child in this advertisement have turned their faces away from the viewer and are looking at each other instead. Kress and Van Leeuwen (1996) term this image an offer image. They are used to display the goodness of the $50 \%$ off offer on the off peak calls that Safaricom is making to the subscribers. The viewer would be attracted to the kind of joy the represented participants are exhibiting and subsequently would be tempted to subscribe to Safaricom limited. We also note that the two represented participants display a far personal distance image aspect. This means that the viewer ought to identify with these participants and by extension, want to also save money by calling during the off peak hours. If such an opportunity of saving air time has arisen then the viewers should not let it bypass them. All they need to do is to join Safaricom subscription and enjoy such benefits.

This fact is further highlighted by the information value of ideal and real. The top part of the advertisement, the ideal, contains the text save $50 \%$ all Easter weekend and every weekend with your off peak calls while the lower part, the real, has the image of a child and an old lady. This means that the image serves an elaborative role by providing a more real and down to earth information. The image, according to the advertisement, wants to make the viewers look at happiness as the most important result of the service offered. This is the service of off peak calls implying a $50 \%$ air time savings.

This advertisement has also applied the concept of Salience. Salience is a descriptive parameter which enables the analysis of the visual social semiotic category of compositional meaning as can be noted in this advertisement. The 
written message is made outstanding especially the 'SAVE 50\%'. This is made salient to attract the subscribers who are inclined towards saving money from their phone calls. In as much as this advertisement appeals to those subscribers who intend to make savings on their phone credits it also strengthens the concept of family togetherness as the image depicts. We would say that it gives the family lots of happiness when some money is saved and used on things that can sustain their needs. Safaricom also explored the usage of inanimate objects in their intention to reach a wider audience. The objective is to capture the attention of the viewer hence make sales as well as provide information.

\section{Conclusion}

Safaricom advertisements employed the meaning making parameters of Representational, Interactive and Compositional meanings as developed by Kress and Van Leeuwen. During the interviews, it was found that without the written words, some of the advertisements could not mean anything to the respondents. They just saw the images as meant to attract them but not communicate any message as expressed by the written word. The play on words as in You talk, We listen, was found to grasp the viewer's attention and stir him to positive action. The rhythm in you talk, we listen are instances of the application of language techniques meant to catch the attention of the audience. It can also be said that Safaricom has exploited the concept of family and love from the exposition stated above. We posit that Safaricom wants the subscribers to feel at 'home' and as part of the company. They want to appeal to the most basic unit of human relationship. For instance, the mother's gaze in advertisement \# 2 rests on the child thus she is her mother's object (goal) of interest. The $50 \%$ savings concept is surpassed by the love and sense of family unity evident in the advertisement.

\section{References}

Cook, G. (1992). The discourse of advertising. London: Routledge and Kegan Paul.

Crystal, D. (1997). The English language. New York: University of Cambridge Press.

Dyer, G. (1982). Advertising as communication. England: Clays Ltd, St. Ives Plc.,.

Fairclough, N. (1992). Discourse and social change. Cambridge: Polity Press.

Fairclough, N. \& Wodak, R. (1997). Critical discourse analysis: Discourse as social interaction Ed. Teun Van Dijk. London: Sage, 258284.

Harris, R.J., Dubitsky, T.M. \& Bruno, K.J. (1983). Psycholinguistic studies of misleading advertising. In R.J. Harris (Ed) Information Processing Research in Advertising, pp132-133. Hillsdale, N. J.: Erlbaum,

Harris, R. J. (1999). A cognitive psychology of mass communication. Mahwah, NJ: Erlbaum Associate.

Haliday, M.A.K. (1985). An Introduction to functional grammar. London: Edward Arnold.

ledema, R. (2003). Multimodality, resemotization: Extending the analysis of Discourse as Multi-semiotic Practice. In Jewitt, C., Van Leeuwen T. Scollon, R. and Triggs, D. (Eds) Visual Communication, pp 37, Sage Publications.

Jeffkins, F. (1994). Advertising. London: Pittman Publishing.

Jewitt, C. \& Oyama, R. (2001). Visual Meaning: A Social Semiotic Approach. In T. Van Leeuwen and C. Jewitt (eds.), A Handbook of Visual Analysis. London: SAGE Publishers.135-155.

Jones, R. H. (2012). Multimodal Discourse Analysis. The Encyclopedia of Applied Linguistics. Retrieved online on $15^{\text {th }}$ June, 2014 www.onlinelibrary.wiley.com

Kress, G. and Van Leeuwen, T. (1996) Reading images: The grammar of visual design. London: Routledge,.

Leiss, W., Kline S. and Jhally, S. (1986). Social communication in advertising. London: Routledge.

Martinec, R. (2001). 'Interpersonal resources in action', Semiotica 135(1/4): 117-45.,

McDonald, C. (1992). English Language Project Work. London: Macmillan Press Ltd.

Muchura, A.W., (2004. Textual Function of style in advertising using women images in Kenyan magazines .Unpublished M.A. Thesis; University of Nairobi.

Ombongi, J. N. (2003). Interpersonal function of style in Kenyan newspaper advertisement. Unpublished M.A. Thesis; University of Nairobi.

Omondi, O, (2006.). Language use and mode of communication in community development projects in Nyanza province, Kenya. Unpublished Phd Thesis; University of the Western Cape.

Schiffrin, D. (1994). Approaches to discourse. Oxford: Blackwell. 
